The Geneva Papers on Risk and Insurance, 16 (No. 61, October 1991), 493 - 499

\title{
Uniform Liability Rules for Service Providers : A Preliminary Comment
}

\author{
by Werner Pfennigstorf*
}

\section{Introduction}

The goal of the European Communities (EC) to create a common market for goods and services presents formidable challenges for politicians, businessmen and lawyers. Generally, the challenges have been met with a combination of political determination, skill, ingenuity, and with astounding success.

The common market has become a reality for the majority of manufactured goods and for most services. A powerful economic momentum demands ever closer approximation of market conditions even where traditional regulatory restraints proved stubborn and even as new problems have arisen from the addition of new members to the Community.

Rather than relying on this inherent momentum, the Commission and the Council of the EC have recently pursued a policy of setting new and higher integration goals, with progressively shorter deadlines for meeting them.

The proposal for a directive on the liability of suppliers of services ${ }^{1}$ is a case in point. Starting with a first draft in May 1989 and supported by a Council Resolution of 9th November 1989 , in which promotion of the safety of services was declared important for consumer protection, the Commission took little more than one year to submit a final proposal to the Council. Within two years, until 31st December 1992, the proposal is expected to be discussed and approved in the Economic and Social Committee and the European Parliamcnt, and to be discussed and adopted by the Council, and the member states are expected to make the necessary changes in their national laws.

Compared to the long gestation period of the products liability dircctive, which took about ten years from formal proposal to final adoption by thc Council and which five years later had yet to be incorporated into the national laws of some of the member states, the time frame proposed for creating uniform national rules for providers of services is nothing short of breathtaking.

* Werner Pfennigstorf. Dr. jur. habil., M.C.L., is an Attorney and Consultant practicing in Düdenbüttel (near Hamburg), Germany.

I Proposal for a Council Directive on the liability of suppliers of services. COM(90) 482 finalSYN 308, submitted by the Commission on 9 November 1990. OJ No. C 12 of January 18. 1991, p. 8. 
This timetable has the appearance not of deliberate dispatch but of undue haste. It has adversely affected the level of care with which the proposal has been drafted and edited. It is not conducive to careful study and discussion of all the legal and public policy issues involved. It will not permit the extensive negotiations that will be necessary to resolve disagreements among the member states about the issues or simply about the meaning of the words chosen. In regard to the legislative actions to be taken by the member states, it is utterly unrealistic.

The following observations identify some of the questions that seem to deserve further thought.

\section{Basic policy and concepts}

In his paper in this issue, ${ }^{2}$ John Cowell ably explains the background, the theoretical bases, the development and the principal provisions of thc proposal. Specifically, he points out that the proposed directive is based on art. 100 a of the Treaty of Rome (added to the Treaty in 1987 by the Single European Act), and consequently, unlike the products liability directive, is designed to achieve two objectives: removal of trade barriers and protection of consumers.

The Commission obviously is of the opinion that the directive as drafted is necessary and appropriate to achieve those purposes, and the preamble so states. The commitment in art. 100 a no. 3 of the Treaty of Rome to "a high level of protection" provides a strong argument in favor of Community-imposed uniform rules whenever they purport to provide a higher level of protection than that provided by existing law in even one of the member states.

One might regret that the Commission obviously has not had sufficient time and inclination to study in detail to what extent and where the current law of each of the individual member states protects consumers with respect to each of the different types of services offered. Such studies, however, are beyond the capabilities of the Commission and in any event would not be likely to have a significant effect on the political decisions that eventually will have to be made by the Council. Modifications are more likely to result from political pressure applied by trade and consumer groups having a special interest in certain types of services.

In this context, it may be remembered how the products liability directive was modified by the addition of exceptions and differentiations to accommodate the special circumstances of certain types of products or transactions.

Among services, there is at least as much variety as there is among products, if not more, and there will be a correspondingly extensive need for differentiation.

Moreover, unlike products, for which a body of coherent case law had already formed in the different member states, there is now no coherent set of rules in any country with respect to services as defined in the Commission's proposal. Rather, vastly differing rules apply to different types of services. Replacing or supplementing all of them with the uniform rules of the proposed directive is certain to present technical problems of adjustment on a larger scale than was the case with respect to defective products.

\footnotetext{
2 Cowell, Geneva Papers this issue, pp. 475-492.
} 


\section{Specifically: scope of application}

The proposal (in art. 2 paras. 2 and 3 ) already names four classes of services to which the uniform rules should not apply: public services to maintain public safety, package travel services, waste services and services covered by international agreements. Dr. Brunn's paper in this issue ${ }^{3}$ deals specifically with such agreements and demonstrates how important it is for world trade to preserve the uniformity already achieved through them.

The list of exempted services will undoubtedly become longer as the proposal winds its way through the EC deliberation process.

The definition and the exemptions raise a series of more basic questions - how the proposed directive defines its scope of application, for what reason and for what purpose, and whether the definition makes sense.

The definition adopted by the proposal is evidently based on the accepted economic dichotomy between trade in goods and trade in services, with the intent to cover all injuries or damage to consumers that are not already covered by the products liability directive.

This approach suffers from two basic conceptual defects: First, the definition of "service" in the proposal is linked to transactions while the liability under the product liability directive is independent of a transaction and is linked only to the fact that a defective product was placed in the stream of commerce, and is limited to injuries or damage caused by the product.

Thus, second, in focusing on the (primarily economic) distinction between goods and services, the proposal fails to recognize another important distinction - that between injuries caused directly by the product or service that is the object of the transaction, and those caused otherwise in the course of the contacts that precede, accompany or follow the transaction or the delivery of the goods or the performance of the services.

The number and variety of such injuries are by no means insignificant. The most frequent type consists of slip-and-fall accidents of customers in department stores and other business premises. The victim may just have purchased an item, or may have intended to purchase an item, or may have come into the shop just to look around, without any intention to purchase anything. Because in the latter two cases no contractual relationship has been established, the courts at first had some trouble finding appropriate solutions; now it is recognized almost everywhere that the owners of business establishments owe their customers a duty to minimize the danger of accidents. In practice, the level of care imposed by the courts in some countries approaches strict liability.

The products liability directive quite clearly was not meant to apply to such collateral accidents. They remain under the general liability regimes of the member states.

Where services are promised, principal and ancillary duties are not as easily separated. The precise equivalent to a product liability case would be a healthy tooth damaged by a dentist in working on a cavity in another tooth, or a window pane shattered by a window washer.

\footnotetext{
${ }^{3}$ Brunn, Geneva Papers this issue, pp. 500-503.
} 
If service providers' liability were to be restricted in the same manner as products liability, it would not apply to the injuries suffered by the dentist's patient falling off a faulty chair, nor to the light fixture shattered by the window washer.

Previous drafts of the service providers' liability directive could have been interpreted as being thus limited, inasmuch as they referred to "defective services". The current proposal no longer uses this term (except in one place in the preamble, where it was probably left only by an editorial oversight).

Rather, article 1 no. 1 of the current draft now refers to a "fault committed" by the provider "in the performance of the service". This suggests reliance on broadly-conceived duties of care rather than a narrow concept of defect similar to that of the products liability directive.

Indecd, a directive restricted to injuries causcd directly by the service as such, as distinguished from the provider's conduct during the underlying transaction, or by the condition of the provider's premises or equipment, would do little to achieve the policy goals set by article $100 \mathrm{a}$ of the Treaty of Rome. Moreover, it would be an invitation to litigation about fine and difficult distinctions.

For instance, while a public carrier's service, viewed most narrowly, consists of nothing more than taking a person from one place to another place, carriers have long been held to owe their passengers a duty to maintain their means of transportation in a safe and seaworthy or roadworthy condition. If the carrier takes its passenger to the desired destination but injures him on the way, this would be an injury for which the proposal in its present form would want to hold the carrier liable, provided it cannot prove the absence of a "fault".

Similarly, the service provided by the operator of a motion picture theater would have to be understood, under the proposed directive, to include furnishing a viewing room with entrance and exit ways offering reasonable safety to patrons.

Thus, as presently worded, the proposed directive would give the benefits of presumed fault to a customer falling on the slippery floor of a hotel or a bank but not to a customer falling on the floor of the bakery or ice cream parlor next door, where the underlying transactions have as their object not services but the manufacture or sale of goods.

To find a rcasonable solution to this absurdity, it is necessary to recognize that all business transactions, whether they have as their "exclusive object" (more correctly: as their principal, or essential object) the provision of a service or the manufacture of goods or the transfer of rights in rem or of intellectual property rights, also necessarily contain, in addition to their principal objective, a service elcment or at least personal contacts that may lead to accidents resulting in personal injury or property damage unrelated to the nature or quality of the product sold or the service provided, and from which therefore duties of care arise to minimize the danger of such injuries.

Article $100 \mathrm{a}$ of the Treaty of Rome applies equally to all consumer transactions; it does not provide a basis for withholding from consumers of goods the protection that is bcing accorded consumers of services.

Rather, if consumers are to be protected against injury or loss and if liability rules arc to be made uniform in the intercst of undistorted competition, there is no reason not to do 
this generally for all consumers who suffer injury or loss as a result of a fault on the part of the seller or provider in the course of making or carrying out the transaction.

There must, of course, be an exception recognizing the existing liability regime for defective products. It needs to be defined in much narrower terms, however, following precisely the scope of application of the products liability directive.

\section{Specifically: Defining "fault"}

The current proposal, unlike earlier drafts and unlike the products liability directive, does not attempt to establish strict liability linked to the concept of "defect". Thereby the draftsmen of the proposal recognize the well-known problems of defining "defect" in the area of products liability and the much greater problems of defining the concept with respect to services.

However, by relying instead on the notion of "fault" and by imposing on the service provider the burden of proving the absence of such fault, the proposal only gives the unavoidable problems a different name.

The court, or other finder of facts, will need standards on which to determine what constitutes fault and on which consequently to determine what facts a service provider would have to prove in order to escape liability in a given case.

Article 1 para. 3 of the proposal refers to the "safety which may reasonably be expected". This standard is similar to the one used for defining "defect" in the products liability directive. With respect to products, it was possible to rely on a well-established body of case law and doctrine concerning various types and elements of "defect".

For services, no corresponding concept has yet evolved. In its place, the definition of article 1 para. 3 would have to receive substance and meaning primarily by continuing the standards relating to the duties of care imposed on businessmen, professionals, property owners and others by the courts in many countries, either as an extension of contractual duties or under the general principles of tort law.

Such court-imposed duties or standards of care have been developed on a case-by-case basis for different transactions, establishments, professions, and situations. They are, moreover, in a state of flux, constantly being adjusted to changes in technology and subject to constant pressure for upgrading in response to rising consumer expectations.

Consequently, as long as different national courts continue to decide independently whether in a given case there was "fault" on the part of the provider, legislation following the proposed directive is not likely to make decisions in actual cases instantly any more uniform than they are now.

Paragraph 4 of article 1 implies that a "better" (rather: higher-priced) service may also be safer; it makes clear, like the corresponding provision in the products liability directive, that this fact alone does not raise the safety standards for all services. It does not, on the other hand, lower the minimum safety level below that which is reasonably required even for the lowest-priced services.

To achieve more actual uniformity, it would be necessary to establish more specific standards of "fault" at least for some classes of services. 
A need for more precise standards would seem to exist especially with respect to medical services. On the one hand, this is an area where the need to protect consumers from injury is obvious and urgent, and where injured persons are at a particular disadvantage when trying to pursue a liability claim against a physician or a hospital. On the other hand, this is an area where it is more important and more difficult than with other types of services to distinguish between accidents, mistakes, and unavoidable adverse results of proper treatment.

Thus, while it is generally recognized that patients should be able to obtain, without having to overcome unreasonable barriers of proof, compensation for injuries resulting from mistakes or avoidable accidents, and while indeed the number of successful medical liability claims has been increasing disproportionately in many countries, it is also recognized that compensation must be kept within reasonable limits and that litigation must be minimized.

In pursuing these goals, various measures have been taken by legislation or otherwise. Sweden has replaced the traditional liability regime with a self-contained patient insurance scheme, which has been closely studied for possible adoption by other countries. In Germany, screening panels have been established to facilitate out-of-court settlements. In the United Kingdom, the British Medical Association has appealed to the government to establish a no-fault compensation scheme for medical treatment injuries.

The directive would have to leave such existing special schemes and standards unaffected, or else would have to replace them with new uniform special standards for medical treatment injuries. The latter would, of course, considerably impair the chances for an early adoption of the directive.

Special liability rules have evolved in some countries, by legislation or case law, for other types of services, such as ski slopes, ice rinks, amusements parks, child care facilities and nursing homes. Should the proposed directive be adopted as presently worded, without reservation regarding such special regimes, there would be doubt about its effect and about the extent to which the member states would have to modify their special legislation.

\section{Specifically : Limitation to injury and property damage}

A client who slips on a loose carpet in his solicitor's office where he was seeking advice on a tax matter, will be able to hold the solicitor liable for his injuries under the proposed directive. The directive would not help him, however, to recover the loss caused by the wrong advice the solicitor gave him. Article 4 restricts the recoverable loss to that resulting from personal injury or damage to property.

Neither the goal of consumer protection under article $100 \mathrm{a}$ of the Treaty of Rome nor that of creating equal conditions for competition in services requires or justifies the exclusion of "pure" economic loss. The effect on the individual consumer may be equal or worse. In the case just mentioned, the economic loss resulting from faulty professional advice may ruin the client while the cost of the injury, including any temporary loss of income, is likely to be covered by insurance.

Indeed, the categories of services where personal injury or property damage to consumers is a relevant danger constitute a relatively small group among commercially offered services. For consumers of many other categories of services, including some of the 
economically most important ones, such as financial services, consulting, publishing, communications, and intermediaries, the risk of injury or property damage is negligible compared to the risk of financial loss through faulty service.

If uniform liability rules are needed to prevent distortions of competition, they are needed with respect to pure economic loss no less than with respect to personal injury or damage to property.

\section{Conclusion}

The proposed directive on the liability of suppliers of services is a perfect example of the dangers of hasty drafting. It also suffers badly from insufficient theoretical groundwork.

That uniform liability rules are desirable in the interest of consumers and in the interest of competition cannot be disputed and is well supported by the basic documents of the EC. The proposal fails, however, to properly recognize the nature and sources of the risk of injury to consumers, it fails to recognize the differences among the services offered and the extent to which they affect the risk of injury or loss, and it fails to take proper account of the different liability regimes existing in the EC member states for specific categories of service.

The proposal requires much work before it could be safely adopted. Should it be adopted for political reasons without the necessary improvements, it can safely be expected to cause great problems in implementation in the individual member states, to make providers and consumers of services miserable and to keep only lawyers happy for a considerable time. 